\title{
Mesangioproliferative Glomerulonephritis: A 30-Year Prognosis Study
}

\author{
Mette Axelsen ${ }^{a, b}, d \quad$ Robert Smith Pedersen ${ }^{b} \quad$ James Goya Heaf ${ }^{c}$ \\ Torkell Ellingsen ${ }^{a}$ d \\ ${ }^{a}$ Institute of Public Health, Aarhus University, Aarhus, ${ }^{b}$ Department of Internal Medicine, \\ Ribe County Hospital, Esbjerg, 'Department of Nephrology B, Herlev Hospital, University of \\ Copenhagen, Copenhagen, and ${ }^{\mathrm{d} D i a g n o s t i c}$ Center, Regionhospital Silkeborg, \\ Silkeborg, Denmark
}

\author{
Key Words \\ Primary diffuse mesangioproliferative glomerulonephritis · Renal survival · Prognostic \\ factors $\cdot$ Cox regression analysis
}

\begin{abstract}
Background: Diffuse mesangioproliferative glomerulonephritis (MesP) is the most commonly diagnosed type of glomerulonephritis (GN) in Denmark, with an incidence of 10.8 million per year. In the present study, the 30-year renal survival was estimated. Methods: A retrospective cohort investigation of 140 patients with biopsy-proven MesP was performed between the period 1967-2006. Factors influencing renal survival were investigated using Cox regression analysis. Results: Renal survival at 5, 10, 20 and 30 years was 87, 78, 59 and 50\%, respectively. Female survival after 30 years was significantly better than male survival ( 70 vs. $40 \%$, $p=0.049$ ). Multivariate analysis, adjusted for age, estimated glomerular filtration rate (GFR) and nephrotic syndrome (NS) was performed for each sex individually. An increase in GFR was associated with a hazard risk (HR) of $0.98(p=0.02)$ in women and $0.99(p=0.006)$ in men. Older age was associated with a HR of $1.04(p=0.02)$ in women and $1.03(p=0.004)$ in men. NS had a poorer prognosis in men (HR 2.53, $p=0.01$ ), but not in women (HR 0.54, $p=0.38$ ). Conclusion: Increasing age and decreasing GFR were adversely associated with renal death. Renal prognosis was better for women after 30 years, and NS resulted in a poorer prognosis in men. This suggests that disease course and prognosis are different between men and women.
\end{abstract}




\section{Introduction}

Glomerulonephritis (GN) is the third commonest cause of renal failure in Europe and the USA [1]. The incidence of biopsied GN in Denmark is 39 million per year [2]. Diffuse mesangioproliferative glomerulonephritis (MesP) is the most commonly diagnosed form of GN in Denmark with an incidence of 11 million per year [2]. MesP has a good prognosis. Previous studies, based mainly on light microscopic diagnosis, show a renal survival after 5 and 10 years of observation varying between $80-96$ and 64-83\%, respectively [3-5], and a 20-year survival of $59 \%$ [4].

Renal survival is negatively associated with age at baseline [3, 6], S-creatinine [3-6], low S-albumin [4, 6], blood pressure (BP) [3, 6] and proteinuria [3-6]. The observation period in the above studies was 3-12 years, with follow-up survival analyses for 3-20 years. The observation period in the present study is more than 40 years. We performed the study to determine whether there was any correlation between renal survival and baseline clinical characteristics (age, sex, S-creatinine, proteinuria, and BP).

\section{Materials and Methods}

A retrospective study was performed in all patients with histologically verified MesP at the Departments of Nephrology of the Aarhus Municipal Hospital, Aarhus, and Ribe County Hospital, Esbjerg, Denmark, between the period 1967-2006. The WHO classification was used [7]. A total of 140 of 633 patients diagnosed with GN were included.

Immunofluorescence investigation was performed in 100 patients and electron microscopy in 72 patients. In March 2011, the outcome (dialysis/transplantation/death) was registered from the hospital files and the Danish Nephrology Registry (DNR). The DNR includes all patients with renal failure, and is fully comprehensive since January 1, 1990. Patients diagnosed with secondary GN, with renal disease as part of a systemic disease (e.g. diabetes mellitus, systemic lupus erythematosus and vasculitis) were excluded.

All biopsies were evaluated by two pathologists (late Prof. S. Olsen and Prof. N. Marcussen). The WHO classification includes 10 types of GN [7]. The primary evaluation used light microscopy. After the introduction of the new classification system in 1982, all biopsies were reevaluated in accordance with the new system. The histological technique was as previously described [8].

There were no defined biopsy indications, so the patients were evaluated individually. Patients with nephrotic syndrome (NS) were routinely offered renal biopsy. The patients received symptomatic treatment and treatment of concurrent hypertension, cardiovascular disease, etc. Immunosuppressive therapy in the form of prednisone, azathioprine and cyclophosphamide was only rarely used $(n=9)$. The baseline was defined as the day of biopsy. The following baseline data were registered: age, sex, proteinuria, BP and S-creatinine. (1) Proteinuria: The patients were divided into two groups: little/no proteinuria and NS. NS was defined as suggested by Glassock et al. [9]: a gradually developing condition characterized by severe proteinuria, usually more than $3.5 \mathrm{~g} /$ day in adults, accompanied by varying degrees of hypoalbuminemia, fluid retention, hypertension and hyperlipidemia. (2) BP: The patients were divided into two groups: normal BP $(\leq 140 / 90 \mathrm{~mm} \mathrm{Hg})$ and raised $\mathrm{BP}(>140 / 90 \mathrm{~mm} \mathrm{Hg}$ ). All patients receiving antihypertensive therapy were classified as hypertensive. (3) S-creatinine: In addition to evaluating S-creatinine as a continuous variable, the patients were divided into two groups: normal and raised. In females, a raised creatinine was defined as $>108 \mu \mathrm{mol} / \mathrm{l}$ and in males as $>125 \mu \mathrm{mol} / \mathrm{l}$. In children aged under 15 years, a creatinine level above the 97.5 th percentile for age plus $20 \%$ was defined as 
raised [10]. The glomerular filtration rate (GFR) was estimated using the following MDRD formula [11]:

$\mathrm{GFR}=175 \times(0.742$ if female $) \times$ creatinine $(\mathrm{in} \mathrm{mg} / \mathrm{dl})^{-1.154} \times \mathrm{age}^{-0.203}$.

There were no Afro-Americans in this population. Renal death was defined as the first occurrence of either maintenance dialysis, renal transplantation or death. No differentiation was made between death due to renal disease and death due to other causes.

Permission was obtained from the Danish Data Protection Agency (j. No. 2010-41-5547), the National Health Ministry (j. No. 7-604-04-2/231) and the DNR.

\section{Statistical Analysis}

Categorical variables were analyzed using the $\chi^{2}$ test. Normally distributed continuous variables were presented as mean \pm standard deviation (SD), and compared using the unpaired Student $\mathrm{t}$ test. Nonnormally distributed continuous variables were presented as median and interquartile ranges (IQR), and evaluated using the Mann-Whitney test. The relationship between baseline characteristics and renal survival was studied using the KaplanMeier survival analysis. Differences in survival were evaluated using the log-rank test. The presupposition of proportional survival was checked by comparing the observed KaplanMeier survival curves with the predicted curves for the same variable. In case of nonproportional survival curves, an interaction test was carried out to evaluate homogeneity. Stratified multivariate analysis was only carried out if no significant differences in hazard risk (HR) were shown. The prognostic factors which were found to be significantly associated with renal survival were included in the multivariate Cox regression analyses. Probability values $<0.05$ were regarded as significant. Follow-up was censored at maximum 30 years. Statistical analysis was performed using Stata, version 11.0 (StataCorp, College Station, Tex., USA).

\section{Results}

The baseline clinical characteristics at the time of biopsy are listed in table 1 . The male:female ratio was $1.7: 1$ and the mean age was 34 years. A total of $47 \%$ of the patients were younger than 30 years. NS was found in 19\%, while 30\% suffered from hypertension. The median S-creatinine level was $95 \mu \mathrm{mol} / \mathrm{l}$ and was raised in $26 \%$. The S-creatinine level was significantly lower in women compared to men [81 $\mu \mathrm{mol} / \mathrm{l}$ (IQR 62-111) vs. $98 \mu \mathrm{mol} / \mathrm{l}$ (IQR 81-122), $\mathrm{p}=0.02]$. There was no difference in the incidence of raised creatinine $(\mathrm{p}=$ 0.83 ) or GFR ( $p=0.72)$. There were no significant gender differences regarding age, BP or proteinuria at biopsy.

\section{Renal Survival}

The mean follow-up time from renal biopsy to event or lost-to-follow-up was $18 \pm 11$ years [range 0.01-43.3, median 16.1 years (IQR 10.3-24.3)].

Survival after 5, 10, 20 and 30 years was 87\% (95\% CI 80-92), 78\% (95\% CI 71-84), 59\% (95\% CI 49-67), and 50\% (95\% CI 40-59), respectively (table 2). After 5 years, there was a nonsignificantly better survival in men ( 91 vs. $81 \%, p=0.08$ ). The 10 -year survival was similar $(\mathrm{p}=0.89)$. Thereafter, women had a better prognosis, becoming significant at 30 years $(p=0.049)$. Survival curves were nonproportional for males and females (fig. 1). The following variables were significantly associated with survival in univariate analysis and were included in the multivariate Cox regression analysis for age, GFR and proteinuria.

The hazard ratio was estimated separately for males and females due to the nonproportionality of survival. In both sexes, risk of renal death was significantly associated with age and GFR. NS was borderline significantly associated with increased risk in both sexes on a 
Table 1. Baseline clinical characteristics

\begin{tabular}{|c|c|c|c|c|}
\hline Characteristic & All & Male & Female & $\mathrm{p}$ value $\mathrm{a}^{\mathrm{a}}$ \\
\hline Gender, $\mathrm{n}$ (\% of males) & $140(63)$ & 88 & 52 & \\
\hline Mean age $\pm S D$, years (range) & $34 \pm 18(5-80)$ & $35 \pm 18(5-71)$ & $33 \pm 18(10-80)$ & $0.56^{\mathrm{b}}$ \\
\hline <30 years, n (\%) & $66(47)$ & $37(42)$ & $29(56)$ & $0.12^{\mathrm{d}}$ \\
\hline Median S-creatinine, $\mu \mathrm{mol} / \mathrm{l}(\mathrm{IQR})$ & $95(72-121)$ & $98(81-122)$ & $81(62-111)$ & $0.02^{\mathrm{c}}$ \\
\hline S-creatinine & & & & $0.83^{\mathrm{d}}$ \\
\hline Normal & $103(74)$ & $65(75)$ & $38(73)$ & \\
\hline Increased & $36(26)$ & $22(25)$ & $14(27)$ & \\
\hline Missing & 1 & 1 & & \\
\hline Mean GFR \pm SD (range) & $80 \pm 42(4-199)$ & $81 \pm 41(4-199)$ & $78 \pm 43(8-138)$ & $0.72^{\mathrm{b}}$ \\
\hline Proteinuria & & & & $0.40^{\mathrm{d}}$ \\
\hline Little/no proteinuria & $112(81)$ & $72(83)$ & $40(77)$ & \\
\hline Nephrotic syndrome & $27(19)$ & 15 (17) & $12(23)$ & \\
\hline Missing & 1 & 1 & & \\
\hline Blood pressure & & & & $0.16^{\mathrm{d}}$ \\
\hline $\mathrm{BP} \leq 140 / 90 \mathrm{~mm} \mathrm{Hg}$ & $98(71)$ & $65(75)$ & $33(64)$ & \\
\hline $\mathrm{BP}>140 / 90 \mathrm{~mm} \mathrm{Hg}$ & $41(30)$ & $22(25)$ & $19(36)$ & \\
\hline Missing & 1 & 1 & & \\
\hline Immunofluorescence & 100 & 67 & 33 & $0.01^{\mathrm{d}}$ \\
\hline IgA positive & $46(46)$ & $37(55)$ & $9(27)$ & \\
\hline IgA negative & $54(54)$ & $30(45)$ & $24(73)$ & \\
\hline
\end{tabular}

Values are n (\%), except where indicated otherwise. ${ }^{\mathrm{a}}$ Difference between genders; ${ }^{\mathrm{b}}$ unpaired t test; ${ }^{\mathrm{c}}$ Mann-Whitney test; ${ }^{\mathrm{d}} \chi^{2}$.

Table 2. Renal survival after 5 , 10,20 and 30 years

\begin{tabular}{rlll}
\hline \multirow{2}{*}{ Time } & \multicolumn{2}{l}{ Renal survival, \% $(95 \% \mathrm{CI})$} \\
\cline { 2 - 4 } & all & male & female \\
\hline 5 years & $87(80-92)$ & $91(83-95)$ & $81(67-89)$ \\
10 years & $78(71-84)$ & $78(68-86)$ & $79(65-88)$ \\
20 years & $59(49-67)$ & $53(41-64)$ & $70(54-82)$ \\
30 years & $50(40-59)$ & $40(28-51)$ & $70(54-82)^{*}$ \\
\hline
\end{tabular}

* Difference between genders $<0.05$.

univariate analysis. However, using multivariate analysis, the HR in men was higher and significant than in the univariate analysis (HR 2.53 vs. $1.95, p=0.01$ vs. $p=0.06$ ), while in women, the opposite was true (HR 0.54 vs. $2.85, p=0.38$ vs. $p=0.05$ ) (table 3 ). An interaction test to evaluate intergender homogeneity showed no significant difference in HR in patients with a raised GFR and a borderline difference in patients with NS when adjusted for other variables (see Appendix table 1).

\section{Discussion}

In this study, the survival rates after $5,10,20$ and 30 years of 87, 78, 59 and 50\%, respectively, are not entirely comparable with previous studies in which varying definitions of baseline, end point and population were used. However, the results do not differ substantially (fig. 2). 


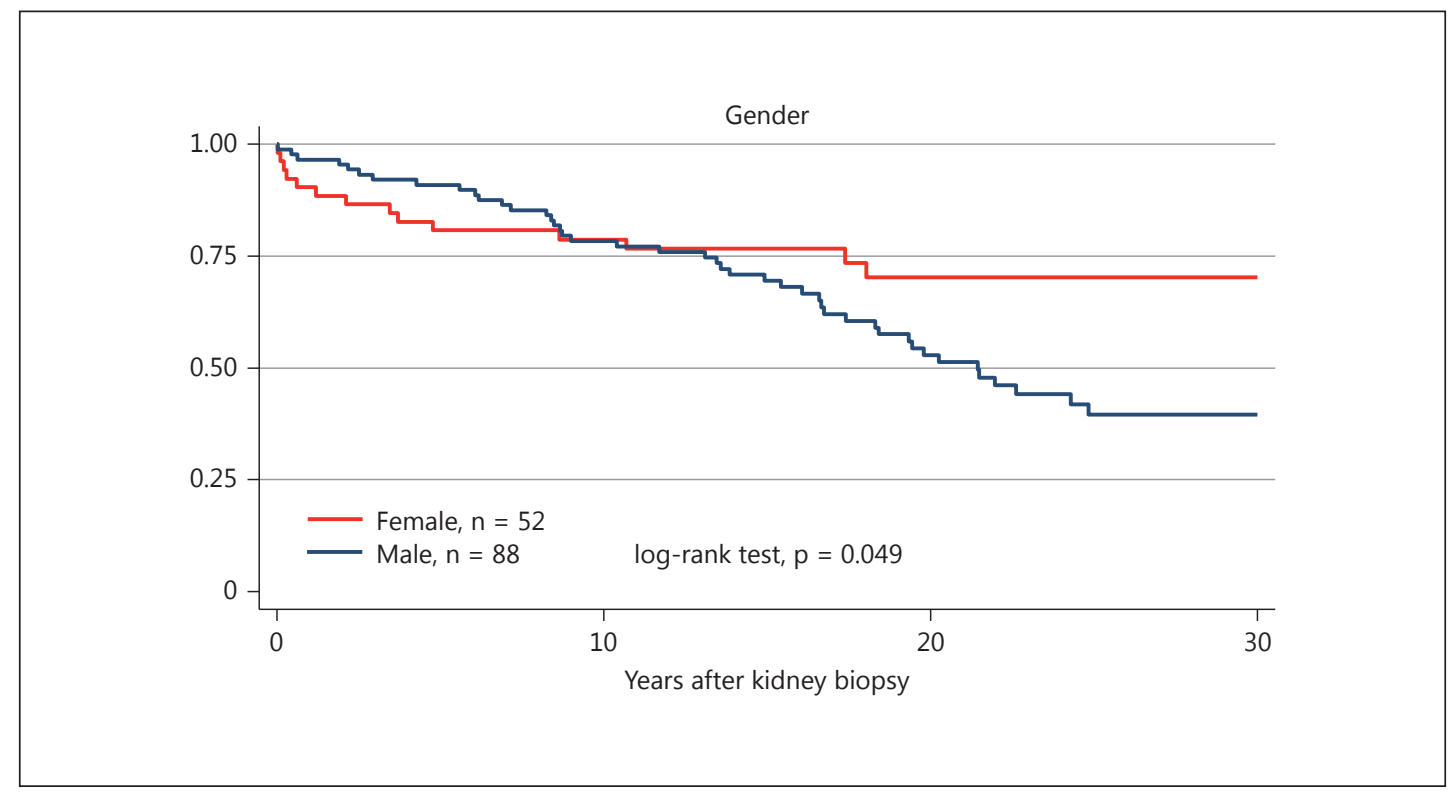

Fig. 1. Kaplan-Meier survival plot illustrating the effect of gender on renal survival.

Table 3. Multivariate Cox regression analysis

\begin{tabular}{lllll}
\hline & \multicolumn{3}{l}{ HR $(95 \% \mathrm{CI})$} & \\
\cline { 2 - 5 } & male & female & combined & $\mathrm{p}$ value \\
\hline Age & $1.03(1.01-1.05)^{*}$ & $1.04(1.01-1.08)^{*}$ & $1.03(1.01-1.05)$ & $<0.001$ \\
GFR & $0.99(0.98-0.99)^{*}$ & $0.98(0.95-0.99)^{*}$ & $0.98(0.98-0.99)$ & 0.001 \\
Little/no proteinuria vs. NS & $2.53(1.24-5.15)^{*}$ & $0.54(0.14-2.12)$ & $1.88(0.99-3.55)$ & 0.05 \\
\hline$* \mathrm{p}<0.05$. & & & & \\
\hline
\end{tabular}

Three independent risk factors were found: age, low GFR and NS. This confirms the previous findings [3-6]. We also found nonproportional survival curves for males and females, with identical survival after 10 years, but significant better survival for females after 30 years. Heaf et al. [2] and Bohle et al. [3] found better 10-year survival in females. The finding was insignificant even if secondary GN cases were included in Heaf et al.'s and in Bohle et al.'s studies. The mean observation period in the present study was 18 years, which enabled the calculation of the 30-year survival. This has not previously been done. The national identity number and DNR permit an exact determination of end points, and data loss after 30 years was rare. GFR at baseline was a powerful prognostic factor for poor survival in both sexes. Many studies of patients with MesP have reported the same finding $[3,4,6]$.

Using a multivariate analysis, NS was a significant risk factor for renal death in males but not females. This analysis has not previously been performed. Bohle et al. [3] found a worse survival in patients with proteinuria $>1 \mathrm{~g}$. Two other studies have also shown a relationship between proteinuria size and prognosis on univariate but not on multivariate analyses $[5,6]$. Proteinuria quantification varied during the period of investigation. Initially urine protein was used, but over time, urine albumin was increasingly used. Therefore, the 


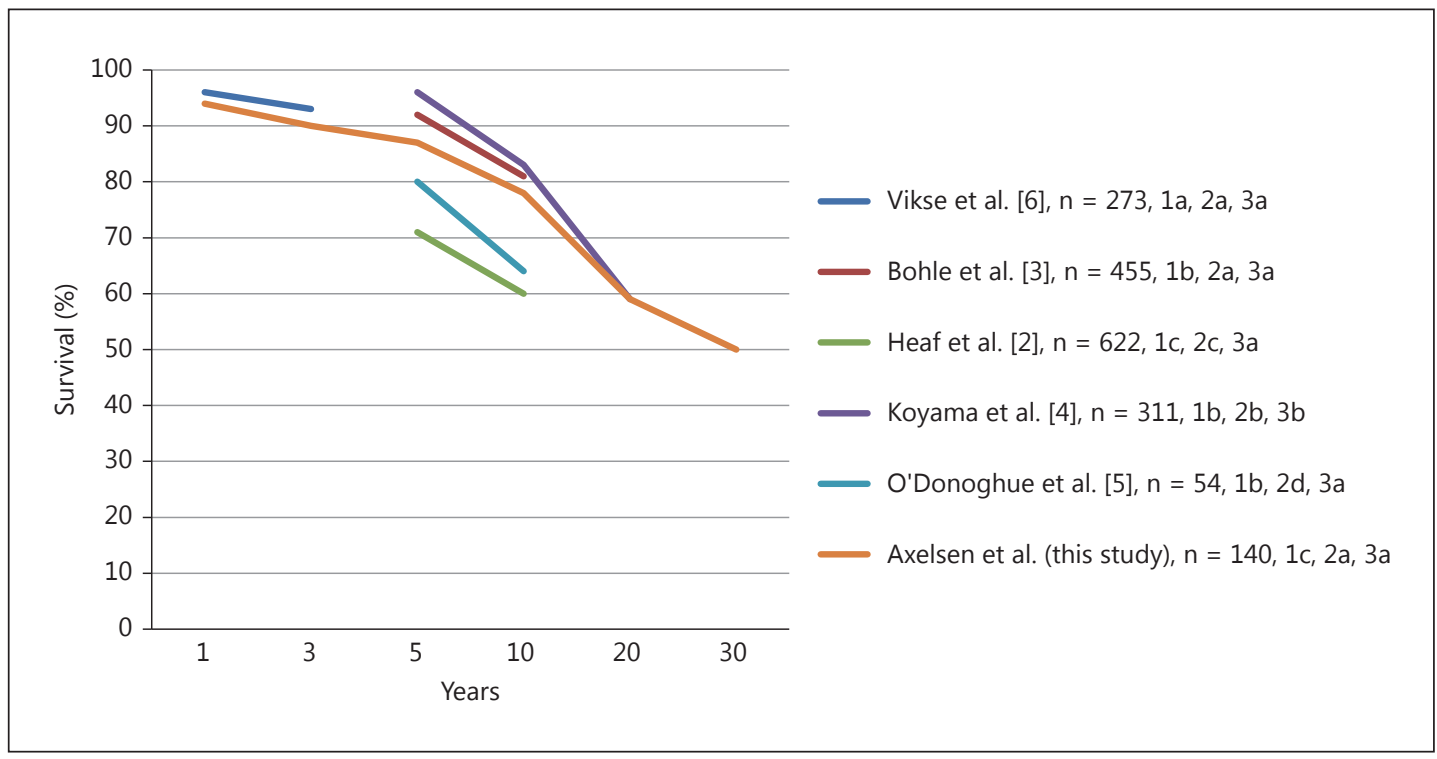

Fig. 2. Survival estimates of MesP GN patients showing the results of six studies. End point: $1 \mathrm{a}=$ Dialysis / transplantation; $1 \mathrm{~b}=$ dialysis/transplantation/renal related death; $1 \mathrm{c}=$ dialysis/transplantation/death. Study population: $2 \mathrm{a}=$ Primary MesP GN; $2 \mathrm{~b}=$ MesP with IgA deposits; $2 \mathrm{c}=$ primary and secondary MesP; $2 \mathrm{~d}=$ MesP with IgM deposits. Baseline: $3 \mathrm{a}=$ Time of renal biopsy; $3 \mathrm{~b}=$ time of symptoms onset.

broad NS definition of Glassock et al. [9] without the use of biochemical analyses was used in this study. One of the paper's strengths is that all biopsies were evaluated by only two experienced pathologists. Furthermore, all biopsies were reevaluated using the WHO classification after its publication. MesP is frequently IgA positive. In Bohle et al.'s [3] paper, 239 of $323(74 \%)$ were IgA positive. IgA had no effect on prognosis. Since immunofluorescence was only performed in 100 of 140 patients in this study, this was not included as a prognostic factor.

One limitation of this paper is that the same definition of hypertension has been used throughout the study period. During the study period, ACE inhibitors have been introduced for several indications: hypertension, heart failure and proteinuria reduction. Therefore, some patients will have been erroneously classified as hypertonic. The indications for renal biopsy have also probably changed during the study period so that more elderly patients with comorbidities have been biopsied. In 2009, Hanko et al. [12] showed that renal biopsy rates in a British region rose from 2 to 7 per 100,000/year between 1976 and 2005, and the average age rose from 33 to 49 years. In the present study, the average age increased from 31.8 to 37.1 years from the first to the second half of the study period.

In Bohle et al.'s [3] study, outcome is defined as patients who died of their kidney disease or developed terminal uremia. Our data do not permit this definition. Patients who, for instance, die of cardiac arrest due to hyperkalemia secondary to renal insufficiency or stroke due to hypertension cannot easily be classified. Therefore, we have chosen to use the combined primary end point death or renal failure. Our main finding was a significant difference in the survival pattern between men and women. Women had a better 30-year survival, and the detrimental effect of NS was greater in men than women (where it was nonsignificant). These findings suggest that the disease course and renal prognosis are different between men and women. 


\begin{tabular}{lllll}
\multicolumn{1}{c}{ Appendix } & \multicolumn{3}{l}{} \\
\hline & Female, HR $(95 \% \mathrm{CI})$ & $\mathrm{p}$ value & Interaction $^{\mathrm{a}}, \mathrm{HR}(95 \% \mathrm{CI})$ & $\mathrm{p}$ value \\
\hline Age & $1.04(1.01-1.08)$ & 0.02 & $0.99(0.95-1.03)$ & 0.61 \\
GFR & $0.98(0.95-0.99)$ & 0.02 & $1.01(0.99-1.04)$ & 0.32 \\
Little/no proteinuria vs. NS & $0.54(0.14-2.12)$ & 0.38 & $4.64(1.00-21.52)$ & 0.05 \\
\hline
\end{tabular}

a Difference between genders (male HR divided by female HR).

\section{Acknowledgements}

We thank statistician Niels Trolle Andersen, Institute of Public Health, Biostatistics, Aarhus University, for assistance and advice regarding statistical analysis; Prof. Niels Marcussen, MD DMSc, Department of Pathology, Odense University Hospital, and late Prof. Steen Olsen, MD DMSc, Department of Pathology, Aarhus University Hospital, for performing the pathology studies.

\section{Disclosure Statement}

The authors have no financial support and no conflict of interest to disclose.

\section{References}

1 United States Renal Data System: 2011 Atlas of CKD \& ESRD, vol 2, p 187. http://www.usrds.org/2011/pdf/ v2_ch01_11.pdf (accessed November 12, 2011).

- Heaf J, Lokkegaard H, Larsen S: The epidemiology and prognosis of glomerulonephritis in Denmark 19851997. Nephrol Dial Transplant 1999;14:1889-1897.

3 Bohle A, Wehrmann M, Bogenschutz O, Batz C, Vogl W, Schmitt H, et al: The long-term prognosis of the primary glomerulonephritides. A morphological and clinical analysis of 1,747 cases. Pathol Res Pract 1992;188:908924.

-4 Koyama A, Igarashi M, Kobayashi M: Natural history and risk factors for immunoglobulin A nephropathy in Japan. Research Group on Progressive Renal Diseases. Am J Kidney Dis 1997;29:526-532.

5 O’Donoghue DJ, Lawler W, Hunt LP, Acheson EJ, Mallick NP: IgM-associated primary diffuse mesangial proliferative glomerulonephritis: natural history and prognostic indicators. Q J Med 1991;79:333-350.

6 Vikse BE, Bostad L, Aasarod K, Lysebo DE, Iversen BM: Prognostic factors in mesangioproliferative glomerulonephritis. Nephrol Dial Transplant 2002;17:1603-1613.

7 Churg J, Sobin LH: Renal Disease. Classification and Atlas of Glomerular Disease. Tokyo, Igaku-Shoin, 1982, pp 67-82.

-8 Pedersen RS: Long-term prognosis in idiopathic membranoproliferative glomerulonephritis. Scand J Urol Nephrol 1995;29:265-272.

9 Glassock RJ, Cohen AH, Bennett CM, Martinez-Maldonado M: Primary glomerular diseases; in Brenner BM, Rector FC (eds): The Kidney. Second edition. Philadelphia, W.B. Saunders Company, 1981, p 1351.

$\checkmark 10$ Ceriotti F, Boyd JC, Klein G, Henny J, Queralto J, Kairisto V, et al: Reference intervals for serum creatinine concentrations: assessment of available data for global application. Clin Chem 2008;54:559-566.

11 Levey AS, Coresh J, Greene T, Stevens LA, Zhang Y, Hendriksen S, et al: Using standardized serum creatinine values in the modification of diet in renal disease study equation for estimating glomerular filtration rate. Ann Intern Med 2006;145:247-254.

12 Hanko JB, Mullan RN, O’Rourke DM, McNamee PT, Maxwell AP, Courtney AE: The changing pattern of adult primary glomerular disease. Nephrol Dial Transplant 2009;24:3050-3054. 